\title{
Punishment and Grace: On the Economics of Permanent Amnesties
}

\author{
Luigi Alberto Franzoni*† \\ DEPARTMENT OF ECONOMICS, UNIVERSITY OF BOLOGNA
}

April 1996

ABstRaCT. This paper extends the literature on tax amnesties by considering two special grace programmes. The first is an offer by the government not to investigate taxpayers' accounts, the second not to prosecute indicted evaders. I analyse the impact of both measures on the taxpayers' optimal behaviour and the government's net revenue, and derive the conditions under which it would be desirable to implement them on a permanent basis.

JEL Nos. H26 (Tax Evasion) and K42 (Illegal Behavior and the Enforcement of Law).

* Correspondence to: Department of Economics, P.zza Scaravilli 2, 40126 Bologna.

tAn earlier version of this paper has benefited from the helpful comments of Chris Harris, Kai-Uwe Kühn, Meg Meyer, Jim Mirrlees and seminar participants at York (RES-93) and Uppsala (ESEM-93). 


\section{INTRODUCTION}

An increasing number of countries have made use of amnesties in recent years, some to overcome the failure of the enforcement apparatus others to surmount urgent revenue needs. Over the last 15 years, tax amnesty programmes have been implemented in 30 states in the US, in Italy, Spain, Ireland, Belgium, France, India, Australia, New Zealand, the Philippines, Columbia, Mexico and Argentina. ${ }^{1}$ On the other hand, many countries regularly provide for voluntary disclosures which carry less severe penalties and serve the role of permanent ("standing") amnesties. Within the OECD, for instance, these provisions are made in all countries except Canada, Finland, Germany, Italy, Japan and Switzerland (OECD 1990). ${ }^{2}$

The bulk of the economic literature on amnesties has so far limited its attention to a type of amnesty that has been relatively popular in the US, which simply provides a chance to pay back evaded taxes. This is probably the type of amnesty providing taxpayers with a "minimal" benefit: in the essence, it merely represents a postponement of the deadline for the submission of the tax return. In reality, amnesties can provide a greater gamut of benefits; from the waiver of interests and civil and criminal penalties on known tax deficiencies, to the provision of complete immunity from investigation and auditing.

The present contribution examines the effects on taxpayers' compliance decisions and the net revenue of amnesties that provide taxpayers with immunity from (standard) prosecution on payment of appropriate compensation. Our focus will be on permanent amnesties, i.e. amnesties whose terms are ingrained in the law or which have become standard practice, and are know in advance by taxpayers. The main concern raised by these enforcement tools relates to their "long-term" effects, and is liked to the problem of whether the apparent speed-up they bring about in the enforcement procedure is worth the increased non-compliance which follows their introduction.

Our results will be twofold: we will show, on the one hand, that amnesties can effectively serve as a screening device, allowing the administration to identify taxpayers with

\footnotetext{
${ }^{1}$ For an overview of recent amnesty programmes see Franzoni (1995a), Olivella (1992), Uchitelle (1989), IRS (1987), Yoingco (1987) and Mickesell (1986).

${ }^{2}$ In Italy, a new settlement procedure ("concordato") has recently been introduced, which allows indicted evaders who plead guilty and pay a pre-determined fee to obtain immunity from prosecution. This procedure is intended to stand in for the periodical amnesty programmes.
} 
the highest willingness to pay. On the other hand, we will see that, depending on the timing of the grace offer - before or after audits are initiated - the amnesty may have a positive or negative effect on the allocation of risk and the net revenue. If both these effects are taken into consideration, amnesties will turn out to produce a clear-cut revenue increase only when they are offered before audits are initiated, i.e. when they provide the taxpayer with full insurance against random auditing.

Before proceeding to review the literature on this subject, we will make a simple classification of amnesty measures, depending on the type of benefit they provide. Note that our classification, as well as the subsequent analysis, is restricted to amnesties for income tax evaders. ${ }^{3}$ We shall distinguish between the following measures:

1. Return amnesty. The possibility offered to taxpayers to revise their tax returns with a reduced penalty. The amnesty enables taxpayers to correct their income returns (upwards) and pay the missing taxes. Taxpayers accepting the amnesty are not immune from the investigation and auditing activities of the tax administration.

2. Investigation amnesty: The possibility offered to taxpayers to get exemption from audits on payment of an amnesty fee. This is essentially an offer not to investigate the real amount, or the origin, of the taxable income of the taxpayers who take part in the programme.

3. Prosecution amnesty: The partial waiving of the penalty for caught evaders who, pleading guilty, ease the judicial course. In this case, only the prosecution power of the administration is suspended.

The first kind of amnesty has been extensively used in the US, while the second has been used in Italy (five amnesties between 1973 and 1995), the Philippines (seven amnesties between 1973 and 1986), Bolivia (roughly every two years), Colombia (1987) and Argentina (4 amnesties between 1970 and 1984). ${ }^{4}$ In Mexico and some other Latin

\footnotetext{
${ }^{3}$ In this paper, we do not deal with amnesties which allow for the general "legalization" of unlawful activities (desertion, illegal immigration, unauthorized building, etc.) or amnesties aimed at retrieving illegal assets within the legal world. On the latter type of amnesty see Das-Gupta and Mookherjee (1995).

${ }^{4}$ Despite US programmes were not officially granting immunity from prosecution, the most successful ones were open to taxpayers who had already received a notice of infringement, and included liabilities known to the tax agency ("accounts receivable"). Hence, these amnesties de facto allowed evaders to avert an imminent prosecution. IRS (1987) calculates that $2 / 3$ of the overall amnesty revenue can be actually traced back to accounts receivable.
} 
American countries, the timely submission of the return automatically guarantees immunity from investigation on prior compliance. The third type of amnesty is usually a permanent element in enforcement practice, and is the equivalent of plea bargaining for criminal cases.

As noted before, most contributions to the theoretical literature have primarily dealt with return amnesties. Given the modest benefit provided by this sort of amnesty, the main problem tackled by this stream of literature has been that of explaining why taxpayers would take part in the programme (and pay a fee to revise their return). A possible explanation lies in the fact that the amnesty lowers the effective tax rate on reported income (i.e., the amnesty is extensive). This possibility is explored by Alm and Beck (1990), who employ prospect theory to identify which type of taxpayers are likely to participate in an unexpected programme. Macho-Stadler, Olivella and Perez-Castrillo (1993) develop instead a dynamic model of tax evasion and show that an extensive amnesty which comes unexpectedly to taxpayers may speed the transition towards a regime of stricter enforcement, or even make it instantaneous when the extent of the pardon is large enough. Another reason why taxpayers may participate in a return amnesty, which becomes essential when it is permanent and not extensive, is related to possible information imperfections at the time when the original return is filed. This uncertainty may relate either to taxpayers' future income [Andreoni (1991), Graetz and Wilde (1993)], taxpayers' utility functions [Malik and Schwab (1991)], or the enforcement parameters [Stella (1991)]. Standing amnesties may then furnish an escape against unexpected shocks and provide taxpayers with social insurance.

Investigation amnesties have been analysed by Marchese e Cassone (1992) and Franzoni (1995b). The first paper depicts amnesties as a form of intertemporal price discrimination: depending on their evasion opportunities, some taxpayers prefer to purchase their "fiscal liberation" at the outset by paying their statutory taxes, while others prefer to wait and pay the amnesty fee. The authors show that the amnesty increases the net revenue to the government if it can suitably restrict participation to taxpayers more prone to evasion. ${ }^{5}$ Franzoni (1995b) investigates the properties of the optimal amnesty policy assuming that the amnesty is not permanent and that the government can decide

\footnotetext{
${ }^{5}$ A simple empirical estimation of this model is provided in Cassone e Marchese (1995). It shows that the representative participant in the 1982 Italian amnesty was a systematically evasion-prone taxpayer. The predictions of the present model are compatible with this observation.
} 
the participation fee each time. The amnesty represents here a form of "renegotiation" of the enforcement policy and proves to increase the net revenue only if the latter is not optimally chosen. Cowell (1990) and Chu (1990) analyse enforcement games which bear important similarities to amnesties. Cowell studies how the option of tax sheltering affects the optimal evasion pattern: the relevance of his work is due to the fact that investigation amnesties represent a form of sheltering directly provided by the government. We will come back to some of his results in section 3. Chu analyses the properties of the so-called FATOTA system, which provides taxpayers with the chance of either paying a Fixed Amount of Taxes or face the risk of a Tax Audit. Chu proves that the introduction of the FATOTA system produces a Pareto improvement in enforcement. His result is reproduced, in a different format, in Proposition 2 below.

The third kind of amnesty, the prosecution amnesty, applies to taxpayers who have already received a notice of infringement from the tax administration, and it is meant to ease the prosecution procedure. Despite their prominence in the actual tax enforcement practice, prosecution amnesties have so far received very little attention. In Franzoni (1994), I develop an enforcement model in which the tax administration selects the audit rate and taxpayers simultaneously file their tax returns, and show how a surprise prosecution amnesty can increase the net revenue to the administration. In the present paper, I extend the analysis further and show under which conditions it is worthwhile implementing a prosecution amnesty on a permanent basis.

The outline of the paper is as follows. In the next section, the classical evasion model of Allingham and Sandmo (1972) is introduced and discussed. Section 3 analyses the impact and desirability of investigation amnesties, while section 4 is devoted to prosecution amnesties. Section 5 provides some final remarks and concludes the paper.

\section{THE MODEL}

In this section, a simple model of tax evasion is introduced, which describes taxpayers' behaviour when amnesties are not feasible. Following Allingham and Sandmo (1972), tax evasion is modelled as a portfolio allocation problem: the taxpayer is faced with the problem of which part of his endowment to invest in the risky activity labelled 'evasion.' If the taxpayer does not want to bear any risk, he will report his income in full, otherwise, he will report only a fraction of it and bear the risk of being caught and fined. The problem of the taxpayer is therefore the choice of the optimal tax report, where the reported income 
is taxed at a fixed rate $t$ and evasion is fined at a penalty rate $f$ proportional to evaded taxes. The probability of being discovered is the same for all taxpayers and is denoted by $a$. This is a simplifying assumption justified by the fact that the tax administration (henceforth "TA") cannot infer the actual income of the taxpayer from his return (since different taxpayers have different degrees of risk aversion). The tax and penalty rates, as well as the audit rate, are set by a superior authority and cannot be modified by the TA.

Taxpayers differ from each other according to their income level and their preferences. We assume that the shape of the utility function of each individual is characterized by a parameter $\theta$, which represents his degree of risk aversion. The distribution of income and attributes in the society is described by a continuously differentiable distribution function $G(\theta, y)$ with support $\Theta \times \Upsilon=[\underline{\theta}, \bar{\theta}] \times[0, \bar{y}]$ and positive density everywhere. The size of the population is normalized to one. The TA knows $G$, but cannot identify the different types.

Each taxpayer chooses the tax report that maximizes his expected utility. Tax reports have to belong to the interval $\Upsilon$. The payment to the state from an individual with income $y$ who reports $(y-e)$ is $t(y-e)$ if he is not caught, and $t y+f t(y-e)$ if he is audited and fined. Note that we have implicitly assumed that the TA makes no errors in the determination of the true liability of the taxpayer. The expected utility for a $(\theta, y)$-type is

$$
E U(e)=(1-a) u_{\theta}(y(1-t)+t e)+a u_{\theta}(y(1-t)-f t e)
$$

with $u_{\theta}^{\prime}>0$, and $u_{\theta}^{\prime \prime} \leq 0$ for all $(\theta, y) \in \Theta \times \Upsilon$. The latter condition implies that all individuals are (weakly) averse to risk. The amount of income that each individual will elect to conceal is denoted by $e(\theta, y)$. It can be easily seen that $e(\theta, y)$ decreases (weakly) with both $a$ and $f$. Moreover, $e(\theta, y)$ decreases with $t$ and increases with $y$ if and only if the utility function displays decreasing absolute risk aversion (DARA) [see Allingham and Sandmo (1972) and Yitzhaki (1974)]. For future reference, let $E U(\theta, y)$ be the expected utility that a $(\theta, y)$-type derives from the optimal evasion choice.

We can now use eq.(1) to derive the "evasion rent" from imperfect enforcement accruing to each taxpayer, i.e. the amount that each taxpayer would be willing to pay to switch from a (virtual) system of perfect enforcement to the actual one. ${ }^{6}$ We have

$$
\text { evasion rent: } \quad r_{e}(\theta, y)=[1-a(1+f)] \text { te }(\theta, y)-R P_{e}(\theta, y),
$$

\footnotetext{
${ }^{6}$ Formally, $r_{e}(\theta, y)=\{r \mid u(y(1-t)+r)=E U(\theta, y)\}$.
} 
where $R P_{e}$ represents the risk premium associated with the optimal evasion choice. The value of evasion to each taxpayer is hence equal to the return on evasion (direct gain, te, less expected punishment, $a(1+f)$ te) less the risk premium. We will assume throughout that $1-a(1+f)>0$, i.e. that the net return on evasion (not adjusted for the risk) is positive. Following Yitzhaki (1987), $R P_{e}(\theta, y)$ can be viewed as the "excess burden of tax evasion" imposed on the taxpayer by a system of random audits. It can be easily seen that, for each taxpayer, $R P_{e}(\theta, y)$ increases with the amount of income concealed. Given the comparative statics results on $e(\theta, y)$ reported above, it can be established that the evasion rent is larger if the audit rate and the penalty rate are lower, and if the taxpayer is less averse to risk (i.e. if his utility function is less concave). With DARA utility functions, the evasion rent is decreasing in the tax rate and increasing in income. ${ }^{7}$

With no amnesties, the net revenue collected by the TA is represented by

$$
\begin{aligned}
R & =\underbrace{\iint_{\Theta \times \Upsilon} t[y-e(\theta, y)] d G(\theta, y)}_{\text {tax revenue }}+\underbrace{\iint_{\Theta \times \Upsilon} a(1+f) t e(\theta, y) d G(\theta, y)}_{\text {enf. revenue }}-\underbrace{c(a)}_{\text {enf. costs }} \\
& =t Y-[1-a(1+f)] t E-c(a)
\end{aligned}
$$

where $Y$ represents the aggregate income, $E$ the aggregate amount of income concealed to the authorities, and $c(a)$ the enforcement costs borne by the TA to audit a fraction $a$ of the population. It follows from the previous remarks that the net revenue without amnesties is larger if the penalty rate and the audit rate are larger, if taxpayers are more averse to risk, and if audit costs are lower. With DARA utility functions, the net revenue increases with the aggregate income and the tax rate.

The model described so far is meant to describe the determinants of the evasion decisions under standard enforcement. Next, we introduce the possibility that amnesties are used as an additional enforcement tool.

\section{INVESTIGATION AMNESTIES}

Let us begin by considering an investigation amnesty, i.e. an amnesty which provides immunity from audits to taxpayers who pay the appropriate fee. ${ }^{8}$ The amnesty is offered before any auditing activity is commenced. Since the amnesty is standing, the fee level

\footnotetext{
${ }^{7}$ The proofs of these results follow standard arguments and parallel those given by Cowell (1990).

${ }^{8}$ In theory, the amnesty fee could depend on the income report of the single taxpayer. In such a case, taxpayers would just take into consideration the sum of the taxes and the amnesty fee associated with each report, and select the report with the lowest total payment. This payment would play exactly the same role as our amnesty fee $q$.
} 
is known to taxpayers from the beginning, together with the other parameters of the enforcement policy.

The game between the TA and the taxpayers has now three stages; in the first, the TA selects the amnesty fee, in the second, taxpayers decide which income to report, and, in the third, whether to benefit from the amnesty or not.

Let us begin by considering the problem of taxpayers. They have to take two decisions: which income to report and whether to accept the amnesty or not. If they accept the amnesty, they are exempted from audits and investigations on their tax accounts; if they do not, they are subject to the risk associated with the normal enforcement activity. The taxpayers' best reply function to any given amnesty policy is derived by considering the optimal choice of $e$ conditional on the acceptance of the amnesty.

If the amnesty fee is $q$, the expected utility for a $(\theta, y)$-type who has reported $y-e$ is

$$
E U(e)=\left\{\begin{array}{lr}
(1-a) u_{\theta}(y(1-t)+t e)+a u_{\theta}(y(1-t)-f t e) & \text { if } \text { Notpartic. } \\
u_{\theta}(y(1-t)+t e-q) & \text { if } \text { Partic. }
\end{array}\right.
$$

The taxpayer has to choose his evasion level in view of a possible participation in the amnesty programme. Notice that the expected utility for a taxpayer who does not intend to take part in the amnesty is the same as in section 2 (enforcement with no amnesty), so that the optimal evasion level for him is $e^{N A}=e(\theta, y)$. On the other hand, the expected utility for a taxpayer who intends to participate is strictly increasing in $e$, so that the optimal evasion is $e^{A}=y$. Since the participation fee is flat, prospective participants have an incentive to conceal all their income and become "ghosts." 9 The decision whether to participate or not is then decided by comparing the expected utilities for the two cases.

$$
\left\{\begin{array}{l}
E U^{N A}(\theta, y)=E U(\theta, y) \quad \text { if } \quad \text { Not partic. } \\
E U^{A}(\theta, y)=u_{\theta}(y-q) \quad \text { if } \text { Partic. }
\end{array}\right.
$$

Hence, the taxpayer prefers to accept the amnesty only if

$$
u_{\theta}(y-q) \geq E U(\theta, y)
$$

The choice of whether to accept the amnesty or not ultimately depends on the shape of the utility function and the income of each taxpayer. Given $q$, taxpayers will be split into two groups: those who plan to accept the amnesty and evade $e^{A}=y$, and those who plan

\footnotetext{
${ }^{9}$ This is true, of course, if the amnesty programme is not restricted to individuals who have filed a return. If this were the case, prospective participants would simply conceal the maximum amount of income compatible with their participation in the programme.
} 
to reject the amnesty and evade $e^{N A}=e(\theta, y)$. Taxpayers will decide whether to become prospective amnesty participants or not on the basis of their ex-ante willingness to pay for the amnesty $v_{I}(\theta, y)$,

$$
v_{I}(\theta, y) \equiv\left\{v \mid u_{\theta}(y-v)=E U(\theta, y)\right\}
$$

Since, for each taxpayer, the certainty equivalent of the audit lottery is equal to his income net of the statutory taxes plus the evasion rent, we have

$$
\begin{aligned}
v_{I}(\theta, y) & =t y-r_{e}(\theta, y) \\
& =t y-[1-a(1+f)] \text { te }(\theta, y)+R P_{e}(\theta, y) .
\end{aligned}
$$

$v_{I}(\theta, y)$ represents the amnesty fee that makes a $(\theta, y)$-taxpayer indifferent about participating in the programme or not. If the actual fee is lower than $v_{I}(\theta, y)$, the taxpayer is better off evading his taxes in full and participating in the amnesty. ${ }^{10}$ To sum up, we can write the following.

Proposition 1. The willingness to pay for an investigation amnesty of each taxpayer is equal to his statutory taxes less his evasion rent [eq.(5)].

Taxpayers with a willingness to pay greater that the amnesty fee will evade all their taxes and participate in the amnesty programme, while the others will stick to their optimal evasion choices and elect not to participate.

By recalling the comparative static properties of the evasion rent $r_{e}(\theta, y)$, one can easily establish that $v_{I}(\theta, y)$ is increasing in the audit rate, in the tax rate, in the penalty rate, and in the taxpayer's degree of risk aversion. The effect on $v_{I}(\theta, y)$ of a variation in income is more difficult to sign, and depends on the configuration of the enforcement parameters. ${ }^{11}$

We can now use the willingness to pay $v_{I}$ to index taxpayers. Let $e(q)$ and $y(q)$ be, respectively, the average evasion and average income of taxpayers with willingness to pay $q$, and let $H(q)$ be the fraction of taxpayers not participating in the amnesty, i.e. the cumulative distribution function of taxpayers with a willingness to pay $v_{I}(\theta, y) \leq q$.

\footnotetext{
${ }^{10}$ It can easily be shown that when the amnesty is not expected, the willingness to pay of each taxpayer is equal to $t e(\theta, y)-r_{e}(\theta, y)$, i.e. $a(1+f) e(\theta, y)+R P_{e}(\theta, y)$. In this case, taxpayers do not have time to take full advantage of the programme and cannot benefit from the increased evasion gains provided by the amnesty.

${ }^{11}$ Cowell (1990) obtains the equivalent of equation 5 by assuming that taxpayers who intend to shelter their income have to shelter all of it, because partial sheltering would be a clear indication of evasion to the tax authorities. He proves that $v_{I}(\theta, y)$ is increasing in $y$ if $t(1+f)<1$. See also Chu $(1990)$.
} 
We can now turn to the problem of the TA. Its objective is the maximization of the net revenue,

$$
\begin{gathered}
R(q)=\underbrace{t Y-\int_{0}^{q} t e(v) d H(v)-\int_{q}^{\bar{q}} t y(v) d H(v)}_{\text {tax revenue }}+\underbrace{\int_{0}^{q} a(1+f) t e(v) d \hat{H}(v)}_{\text {enforcement revenue }} \\
+\underbrace{q(1-H(q))}_{\text {amnesty revenue }}-\underbrace{c(a H(q))}_{\text {enforcement costs }},
\end{gathered}
$$

where $\bar{q} \equiv \sup \left\{v_{I}(\theta, y)\right\}$. The TA maximizes $R$ taking into account the best reply of taxpayers, here represented by the functions $e(\cdot)$ and $y(\cdot)$. It can be seen that the number of people engaging in full evasion will be larger if the participation fee is smaller. A reduction in $q$ hence leads to a reduction in the tax revenue, an increase in the amnesty revenue and a decrease in the enforcement revenue and enforcement costs.

The marginal revenue is ${ }^{12}$

$$
\begin{aligned}
R^{\prime}(q)= & -[1-a(1+f)] t e(q) H^{\prime}(q)+t y(q) H^{\prime}(q)+(1-H(q)) \\
& -q H^{\prime}(q)-a c^{\prime}(a H(q)) H^{\prime}(q)
\end{aligned}
$$

so that, using eq. (5) and simplifying, one gets

$$
R^{\prime}(q)=(1-H(q))-H^{\prime}(q)\left[R P_{e}(q)+a c^{\prime}(a H(q))\right]
$$

The marginal revenue associated with a unit increase in the amnesty fee $q$ is equal to the increase in the amnesty intake from inframarginal participants, $1-H(q)$, less the net revenue missed from marginal participants. The latter consists of the amount that marginal taxpayers would be willing to pay to get insurance against the audit risk, $R P_{e}(q)$, and the saving in enforcement cost, $a c^{\prime}(a H(q))$. The problem of the TA therefore resembles that of a monopolist which has to trade-off the gains from the sale of an additional unit with the reduction in payments from inframarginal consumers.

Note that at $q=\bar{q}$, we have $H(\bar{q})=1$, and hence $R^{\prime}(\bar{q})<0$. This proves that the solution is on the interior and satisfies $R^{\prime}(q)=0 .{ }^{13}$

\footnotetext{
${ }^{12}$ The marginal revenue is continuous under the mild condition that the set of points $(\theta, y) \in \Theta \times \Upsilon$ such that $\left\{v_{I}(\theta, y)>0\right.$ and $\left.\nabla v_{I}(\theta, y)=0\right\}$ has measure zero. This assumption guarantees that $H(q)$ varies continuously with $q$.

${ }^{13}$ The first part of the proposition replicates the results of Chu (1990) and Reinganum and Wilde (1985), and represents a variation of the "no-distortion-at-the-top" result in the standard principal-agent model.
} 
Proposition 2. An investigation amnesty proves to increase the net revenue to the tax administration. The optimal amnesty fee $q^{*}$ satisfies

$$
H^{\prime}\left(q^{*}\right)\left[R P_{e}\left(q^{*}\right)+a c^{\prime}\left(a H\left(q^{*}\right)\right)\right]=1-H\left(q^{*}\right)
$$

A marginal amnesty turns out to be profitable since it allows the TA to extract the risk premium from amnesty participants (i.e. to provide them with insurance against audits) and to screen out taxpayers with the highest willingness to pay (and save on the audit cost). The first factor is due to the fact that taxpayers for the amnesty are willing to pay an amount which is larger than the amount that the TA would have collected (in the form of taxes and penalties) under standard enforcement. This wedge is measured by the difference between the value of evasion to individuals and its cost to the TA (the "excess burden of tax evasion"). The second factor is linked to the screening properties of the amnesty programme, which allows the TA to extract resources from taxpayers on the basis of a pure threat (audit and sanction with probability $a$ in case of non-participation). It is clear that a necessary condition for this factor to work is that the TA sticks throughout to the announced policy. ${ }^{14}$ At the optimum, not all taxpayers will be allowed to take part in the programme, since this can be done only by providing free participation and losing all revenue. The optimal amnesty fee will therefore be on the interior and satisfy eq.(7). The net revenue gathered by the TA depends on taxpayers willingness to pay, and increases with their degree of risk aversion, the penalty rate $f$, the audit rate $a$, and, given DARA utility functions, the tax rate $t$.

A permanent amnesty splits taxpayers into two categories: those who get full insurance and evade all taxes due and those who do not get insurance and report their income so as to maximise their evasion rent. Note that the structure of the game is such that it does not matter at which stage taxpayers pay the amnesty fee, before or after incomes have been reported. Note also that, apart from the fee, there are no other transfers from the taxpayers who accept the amnesty to the TA. Therefore, an alternative interpretation of this game is to regard the amnesty fee as the ex-ante 'safety' tax payment. This takes us to the "FATOTA scheme" proposed by Chu (1990): pay a Fixed Amount of Taxes Or incur the risk of a Tax Audit. The fee $q^{*}$ defines the tax payment which provides exemption from tax audits. ${ }^{15}$ The only difference between the FATOTA system and a standing

\footnotetext{
${ }^{14}$ This commitment problem is addressed in Chapter 4 of Franzoni (1995a).

${ }^{15}$ This sort of scheme, which has been in use for more than 20 years in Taiwan, has recently been
} 
investigation amnesty is that with the latter the "grace" for taxpayers complying with the minimum payment comes only ex-post, after tax returns have been submitted and the law has been violated. Although this does not affect the net revenue, it carries strong implications from a legal and normative standpoint, and one should seriously address the question why the immunity from audits is not provided at the outset. ${ }^{16}$

Permanent amnesties, as well as the FATOTA system, have been regarded as devices which lead towards the taxation of "presumptive" income, instead of the actual one. ${ }^{17}$ In reality, the safety payment defined by these enforcement methods should be determined so as to maximize the TA's revenue, and should not necessarily coincide with the tax level associated with the average income of each taxpayer (or category of taxpayers). ${ }^{18}$ Also, this "presumptive" tax is not compulsory: taxpayers can report an income which is less than $q^{*} / t$, and bear the risk of being audited. More precisely, therefore, one should regard the safety income report as a threshold above which income is tax exempted, rather than a presumptive (average) income.

\section{Prosecution amnesties}

In this section, we assume that the amnesty takes the form of a general offer of acquittal for indicted evaders on payment of a fixed fee. The amnesty explicitly addresses evaders who have not yet undergone a definitive judgement, and offers a discount on the expected penalty in exchange for a guilty plea. This allows the administration to save on the resources necessary to prove the guilt of the defendant, but results in a lower penalty recovery since a fraction of the so-called "accounts receivable" will be lost. Although the amnesty offer can be made at any stage of the prosecution procedure, we will assume that it is made at the beginning of the investigation, when no incriminatory evidence has yet been collected about the single taxpayer. This allows us to ignore all effects due to the actual shape of the information acquisition process.

The timing of the game is the following : the TA sets the amnesty fee $p$; taxpayers

introduced in Spain (apparently with great success) for some categories of taxpayers (owners of pubs and taxis).

${ }^{16}$ In the Italian experience, some time usually elapses between the submission of the returns and the amnesty. This means that there is a short time in which taxpayers are inevitably subject to the audit risk.

${ }^{17}$ This is the standard view among Italian scholars. The taxation of presumptive incomes has been generally regarded as an extreme measure, justified only for agricultural or "hard to tax" incomes (Musgrave 1981). On this see also Tanzi (1991) and Das-gupta (1994).

${ }^{18}$ Incidentally, note that the "average" willingness to pay of taxpayers (belonging to a specific category) is equal to their average statutory taxes less their average evasion rent. 
decide which income to report; a fraction $a$ of taxpayers is selected for auditing and offered an amnesty; taxpayers decide whether to accept the offer or not.

Let us begin by considering the taxpayers' problem. Each taxpayer has to choose which amount of income to report and whether to accept the amnesty offer if he is selected for an audit. In the second stage, when he is called upon to choose whether to settle the case on payment of the amount $p$, he will accept only if

$$
p \leq(1+f) t e
$$

where $e$ is the amount of income underreported. Ex-ante, his expected utility is then

$$
E U(e)=\left\{\begin{array}{l}
(1-a) u_{\theta}(y(1-t)+t e)+a u_{\theta}(y(1-t)-f t e), \text { if } \quad \text { Not partic. }, \\
(1-a) u_{\theta}(y(1-t)+t e)+a u_{\theta}(y(1-t)+t e-p), \text { if Partic. }
\end{array}\right.
$$

Since the expected utility in case of participation is increasing in $e$, a taxpayer who intends to participate in the amnesty will choose $e^{A}=y$, while he will choose $e^{N A}=e(\theta, y)$ otherwise, since his optimal evasion choice is not affected by the amnesty. Ex-ante, he will therefore choose between becoming a prospective participant or not depending on the level of the following payoffs,

$$
\left\{\begin{array}{l}
E U^{N A}=E U(\theta, y), \quad \text { if } \quad \text { Not partic. } \\
E U^{A}=(1-a) u_{\theta}(y)+a u_{\theta}(y-p), \quad \text { if Partic. }
\end{array}\right.
$$

The amnesty fee that makes a $(\theta, y)$-type taxpayer indifferent about whether to participate or not, i.e. his willingness to pay, is

$$
v_{p}(\theta, y)=\left\{v \mid(1-a) u_{\theta}(y)+a u_{\theta}(y-v)=E U(\theta, y)\right\}
$$

Taxpayers with a willingness to pay $v_{p}(\theta, y) \geq p$ choose to evade all their taxes and rely on the amnesty in case they are indicted. Note that the willingness to pay of each taxpayer for a prosecution amnesty, $v_{p}(\theta, y)$, is greater than the willingness to pay for an investigation amnesty, $v_{I}(\theta, y)$, since the first is paid when the taxpayer has already been selected for an audit and faces a certain sanction. From eq.(4) it can be seen that

$$
u\left(y-v_{I}(\theta, y)\right)=a u\left(y-v_{p}(\theta, y)\right)+(1-a) u(y)
$$

which shows that $v_{I}(\theta, y)$ is the amount of income that the taxpayer is willing to forgo in order to avoid the risk of losing $v_{p}(\theta, y)$ with probability $a$. As a consequence, $v_{I}(\theta, y)$ is equal to $a v_{p}(\theta, y)$ plus the relative risk premium, $R P_{p}(\theta, y)$. We have therefore

$$
\begin{aligned}
a v_{p}(\theta, y) & =v_{I}(\theta, y)-R P_{p}(\theta, y) \\
& =t y-r_{e}(\theta, y)-R P_{p}(\theta, y)
\end{aligned}
$$


that is

$$
a v_{p}(\theta, y)=t y-[1-a(1+f)] t e(\theta, y)+R P_{e}(\theta, y)-R P_{p}(\theta, y)
$$

Eq.(9) says that the amount that amnesty participants are willing to pay (in expected terms) to join the programme is equal to their statutory taxes less their evasion rent, less the deadweight loss due to the additional risk they have to bear (since they evade their whole taxes in view of the amnesty).

Proposition 3. The expected willingness to pay for a prosecution amnesty of each taxpayer is equal to his statutory taxes less his evasion rent, less the risk premium associated with full evasion [eq.(9)].

Taxpayers with a willingness to pay greater that the amnesty fee will evade all their taxes and participate in the amnesty programme, while the others will stick to their optimal evasion choices and elect not to participate.

By implicit differentiation of eq.(8), it can be established that the willingness to pay of each individual increases with the penalty rate $f$, the audit rate $a$, and, with DARA utility functions, the tax rate $t$.

We can now use the willingness to pay $v_{p}(\theta, y)$ to index individuals. Let $e(p)$ and $y(p)$ be the average evasion and income, respectively, of taxpayers with a willingness to pay $p$, and let $F(p)$ be the fraction of the population with a willingness to pay less than $p$.

The net revenue to the TA can be written as ${ }^{19}$

$$
\begin{array}{r}
R(p)=\underbrace{t Y-\int_{0}^{p} t e(v) d F(v)-\int_{p}^{\bar{p}} t y(v) d F(v)}_{\text {tax revenue }}+\underbrace{\int_{0}^{p} a(1+f) t e(v) d F(v)}_{\text {enf. revenue }} \\
+\underbrace{a p(1-F(p))}_{\text {amnesty revenue }}-\underbrace{c(a F(p))}_{\text {enf. costs }},
\end{array}
$$

where $\bar{p} \equiv \sup \left\{v_{p}(\theta, y)\right\}$. Differentiating and plugging in eq.(9) yields

$$
R^{\prime}(p)=a[1-F(p)]-F^{\prime}(p)\left[a c^{\prime}(a F(p))-R P_{p}(\theta, y)+R P_{e}(\theta, y)\right]
$$

The marginal revenue function collapses to a simple expression, which indicates that a unit increase in the amnesty fee raises the amnesty intake from participants, increases

\footnotetext{
${ }^{19}$ Again, we need to assume that the set of points $(\theta, y) \in \Theta \times \Upsilon \operatorname{such}$ that $\left\{v_{p}(\theta, y)>0\right.$ and $\nabla v_{p}(\theta, y)=$ $0\}$ has measure zero to ensure that $F$ varies continuously with $p$.
} 
the marginal enforcement cost, and allows the TA to net extra resources equal to the reduction in the uninsured risk for marginal participants (who have to bear only the risk associated with the evasion level $e=e(\theta, y)$ rather than $e=y)$.

At $\bar{p}$, we therefore have

$$
R^{\prime}(\bar{p})<0 \Longleftrightarrow a c^{\prime}(a)>R P_{p}(\theta, y)-R P_{e}(\theta, y)
$$

which is not necessarily satisfied. This is because prosecution amnesties, while retaining a screening power, lead prospective participants to evade all their taxes, and thereby increase the deadweight loss due to uninsured risk. If the additional "excess burden of tax evasion" brought about by the amnesty policy is larger than the saving in enforcement costs (due to the self-selection of the taxpayers with the largest willingness to pay), then a (marginal) amnesty is not desirable.

Proposition 4. A permanent prosecution amnesty does not necessarily increase the net revenue to the tax administration.

In the case that amnesty is granted, the optimal participation fee is characterized by

$$
F^{\prime}\left(p^{*}\right)\left\{a c^{\prime}\left(a F\left(p^{*}\right)\right)-R P_{p}(\theta, y)+R P_{e}(\theta, y)\right\}=a\left[1-F\left(p^{*}\right)\right]
$$

Under which conditions is a prosecution amnesty likely to be desirable? If we look at eq.(11), we notice the following. In the first place, an amnesty turns out to increase the net revenue when the marginal enforcement costs are very large. This is likely to be the case when the TA is subject to heavy congestion and when it is unable to cope (at a reasonable cost) with a large number of audits (and possible judicial disputes). Secondly, the negative effect of the amnesty will be small if taxpayers are characterized by a low degree of risk aversion; in the limit, if taxpayers were (almost) risk-neutral, both $R P_{p}$ and $R P_{e}$ would tend to zero. Finally, the amnesty has no adverse effects if prospective participants do not alter their evasion choices in view of the amnesty, i.e. if they already evade their whole income.

A different insight can be obtained by noting that, for the taxpayers who do not take part in the amnesty programme, it must be true that $p>(1+f)$ te $(\theta, y)$, otherwise they would find it profitable ex-post to accept the amnesty. Since the marginal revenue at $\bar{p}$ may also be written as

$$
R^{\prime}(\bar{p})=F^{\prime}(\bar{p})\left[-t(1-a(1+f)) e(\bar{p})+t y(\bar{p})-a \bar{p}-a c^{\prime}(a)\right]
$$


a sufficient condition for a negative marginal revenue is: $a c^{\prime}(a)>t[y(\bar{p})-e(\bar{p})]$, which says that the amnesty is implemented when the loss in tax revenue due to the additional evasion is less than the saving in enforcement costs. Hence, high evasion rates make the amnesty likely to improve the tax revenue.

\section{FINAL REMARKS}

The analysis presented in the previous sections has shown that tax amnesties can differ greatly in form and in the results obtained. The two measures we have focused on, investigation amnesty and prosecution amnesty, provide an escape from the standard enforcement process to taxpayers who admit their infractions and pay a certain fee.

Our results show that both types of amnesty represent effective screening devices which can be used by the TA to reduce its enforcement costs. Amnesties induce taxpayers with the highest willingness to pay to self-select themselves and to elude the standard enforcement/prosecution procedure (which is costly to the administration).

The main difference between the two measures relates to their way of allocating the audit risk: while investigation amnesties can be used to completely insure participants against the risky elements involved in the enforcement policy, prosecution amnesties cannot, since they are offered after taxpayers have suffered from the bad luck of being selected for auditing. In fact, prosecution amnesties increase the risk borne by the participants, since the latter are led to evade a larger fraction of their income and pay a larger amount in case of an audit. For this reason, prosecution amnesties are likely to be desirable only when the TA is congested or the amount of evasion in the system is already very large. 


\section{References}

Allingham, M. G. and A. Sandmo, 1972, Income tax evasion: A theoretical analysis, Journal of Public Economics 1, 323-338.

Alm, J. and W. Beck, 1990, Tax amnesties and tax revenue, Public Finance Quarterly $18,433-453$.

Andreoni, J., 1991, The desirability of a permanent tax amnesty, Journal of Public Economics 45, 143-159.

Cassone, A. and C. Marchese, 1995, Tax amnesties as special sales offers: The Italian experience, Public Finance/Finances Publiques 50, 51-66.

Chu, C., 1990, Plea bargaining with the IRS, Journal of Public Economics 41, 319-333.

Cowell, 1990, Tax sheltering and the cost of evasion, Oxford Economic Papers 42, 231243.

Das-Gupta, A., 1994, A theory of hard-to-tax groups, Public Finance and Irregular Activities, ed. by W. Pommerehne, supplement to Public Finance/Finances Publiques 49, 28-39.

Das-Gupta, A. and D. Mookherjee, 1995, Tax amnesties as asset laudering devices, mimeo.

Franzoni, L.A., 1994, Costly prosecution, tax evasion and amnesties, Economic Notes $23,248-265$.

Franzoni, L.A., 1995a, On the economics of tax amnesties, D.Phil. thesis, Nuffield College, Oxford.

Franzoni, L.A., 1995b, Tax amnesties, settlements, and the optimal enforcement policy, w.p. 221, Dept. of Economics, University of Bologna.

Graetz M. and L. Wilde, 1993, The decision by strategic nonfilers to participate in income tax amnesties, International Review of Law ad Economics 13, 271-283.

Internal Revenue Service, 1987, Study of tax amnesty programs, U.S. Department of the Treasury.

Malik, A. S. and R. M. Schwab, 1991, The economics of tax amnesties, Journal of Public Economics 46, 29-49.

Macho-Stadler, I., P. Olivella and D. Perez Castrillo, 1993, Tax amnesties in a dynamic model of tax evasion, w.p. 247.94, Universitat Autonoma de Barcelona. 
Marchese, C. e A. Cassone, 1992, Tax amnesties as price-discriminating behaviour by a monopolistic government, mimeo.

Mickesell, J. L., 1986, Amnesties for state tax evaders: The nature and response to recent programs, National Tax Journal 39, 507-522.

Musgrave, R. A., 1981, Fiscal reform in Bolivia, Harvard Law School, Cambridge, MA.

OECD, 1990, Taxpayers' rights and obligations: A survey of the legal situation in OECD countries, OECD, Paris.

Olivella, P., 1992, Las amnistias fiscales: Descripcion y analisis economico, Dep. Economia i Historia Economica, Universitat Autonoma de Barcelona, mimeo.

Reinganum, J. and L. Wilde, 1985, Income tax compliance in a principal-agent framework, Journal of Public Economics 26, 1-18.

Stella, P., 1991, An economic analysis of tax amnesties, Journal of Public Economics 46, 383-400.

Tanzi, V., 1991, Public finance in developing countries, Elgar, Aldershot.

Uchitelle, E., 1989, The effectiveness of tax amnesty programs in selected countries, Federal Reserve Bank of New York Quarterly Review, Autumn, 48-53.

Yoingco, A.Q., 1987, Experience with tax amnesty legislation, Bulletin for International Fiscal Documentation 41/4, 172- 180.

Yitzhaki, S., 1974, Income tax evasion: A note, Journal of Public Economics 3, 201-202.

Yitzhaki, S., 1987, On the excess burden of tax evasion, Public Finance Quarterly 15, 123-137. 